\title{
Subserous Eosinophilic Gastroenteritis: A Rare Cause of Ascites
}

\author{
António Araújo Ferreira ${ }^{1}$, Susana Manuela Barbosa ${ }^{1}$, Soraia Oliveira ${ }^{1}$, José Ramada $^{2}$, Augusta Silva ${ }^{1}$ \\ ${ }^{1}$ Serviço de Medicina 1, Unidade Local de Saúde do Alto Minho, EPE, Portugal \\ ${ }^{2}$ Serviço de Gastroenterologia, Unidade Local de Saúde do Alto Minho, EPE, Portugal
}

How to cite this article: Ferreira AA, Barbosa SM, Oliveira S, Ramada J, Silva A. Subserous eosiniphilic gastroenteritis: a rare cause of ascites. EJCRIM 2017;4: doi:10.12890/2017_000586

Conflicts of Interests: The Authors declare that there are no competing interests.

Acknowledgements: The Authors would like to thank Yolanda Mahia, MD of the Pathology Department, Unidade Local de Saúde do Alto Minho, for kindly providing the images, and João Andrade, MD of the Internal Medicine Department, Unidade Local de Saúde do Alto Minho.

This article is licensed under a Commons Attribution Non-Commercial 4.0 License

\section{ABSTRACT}

Eosinophilic gastroenteritis is an inflammatory gastrointestinal disease characterized by eosinophilic infiltration of the digestive tract. The subserous type is the rarest form and diagnosis is challenging because the symptoms are heterogeneous and endoscopy may be non-diagnostic. The authors describe the clinical case of a 41-year-old female patient who was diagnosed with subserous eosinophilic gastroenteritis. This case highlights the importance of clinical suspicion of eosinophilic gastroenteritis in patients in the third to fifth decades of life with gastrointestinal symptoms, ascites and eosinophilia.

\section{LEARNING POINTS}

- Subserous eosinophilic gastroenteritis is an uncommon inflammatory gastrointestinal disease with a challenging diagnosis because the symptoms are heterogeneous and endoscopy may be non-diagnostic.

- The diagnosis should be suspected in the presence of gastrointestinal symptoms, and peripheral eosinophilia is confirmed by the presence of eosinophilic infiltration of the gastrointestinal tract or ascites with a predominance of eosinophils, after the exclusion of other causes of eosinophilia.

- Automated cell counting analysis of the ascitic fluid can wrongly identify eosinophils as neutrophils, which can delay the diagnosis.

\section{KEYWORDS}

Eosinophilic gastroenteritis; ascites; eosinophilia

\section{INTRODUCTION}

Eosinophilic gastrointestinal disorders are a family of uncommon diseases and include eosinophilic oesophagitis, gastritis and enterocolitis. Disease typically occurs during the third to fifth decades of life ${ }^{[1]}$.

The pathogenesis is not well understood, but there may be an allergic component. Histologically, disease is characterized by infiltration of the digestive tract tissues by eosinophils ${ }^{[1]}$.

Clinical manifestations depend on the location, extent and layers of digestive tract involved ${ }^{[1]}$. In disease restricted to the mucosa, symptoms are non-specific and abdominal pain, nausea, vomiting, diarrhoea, weight loss and malabsorption syndrome can occur depending on the area involved. Disease with muscular involvement is mainly characterized by symptoms of intestinal obstruction. 
When there is involvement of the serous layer, the clinical presentation may include isolated ascites or ascites combined with symptoms described in mucosal or muscular disease. Peripheral eosinophil counts are generally increased but may be normal in $20 \%$ of cases ${ }^{[1]}$.

We describe a clinical case of eosinophilic gastroenteritis with isolated involvement of the subserous layer.

\section{CASE REPORT}

A 41-year-old female patient was admitted through the emergency department with increased abdominal volume, anorexia, general malaise and watery diarrhoea for 15 days before admission. The patient had a past history of autoimmune hypothyroidism medicated with levothyroxine $0.1 \mathrm{mg} / \mathrm{day}$. She had no history of allergies, alcohol intake, ingestion of well water, contact with animals or recent trips abroad. On initial evaluation the patient was conscious and vital signs were normal. Abdominal examination showed ascites with no palpable masses or organomegaly. No peripheral oedema, stigmata of chronic liver disease or adenopathy were present. Blood tests revealed leucocytosis $(12,560 / \mu \mathrm{l})$ with 6,280 neutrophils/ $\mu$ land 3,454 eosinophils/ $\mu \mathrm{l}$, C-reactive protein of $2.04 \mathrm{mg} / \mathrm{dl}$, a sedimentation rate of $6 \mathrm{~mm}$ and albumin of $3.3 \mathrm{~g} / \mathrm{dl}$ (Table 1). Clear liquid obtained from diagnostic paracentesis revealed an albumin of $3 \mathrm{~g} / \mathrm{dl}$ and a calculated serum albumin gradient (SAG) below $1.1 \mathrm{~g} / \mathrm{dl}$, suggesting that portal hypertension was not the cause of the ascites. The ascitic fluid $(10 \mathrm{~mL}) \mathrm{contained} 15,646 \mathrm{cells}$ of which 1,846 were leucocytes (neutrophils $75 \%$, monocytes $20 \%$, lymphocytes $5 \%$, no description of eosinophils), total proteins 5.0 g/dl, glucose $92 \mathrm{mg} / \mathrm{dl}$, LDH $140 \mathrm{IU} / \mathrm{I}$, ADA $10.4 \mathrm{IU} / \mathrm{I}$ and amylase $20 \mathrm{IU} / \mathrm{l}$. Abdominal computed axial tomography showed ascites, thickening of the walls of the stomach, duodenum and jejunum, and a suspected nodular pancreatic lesion (Fig. 1).

\begin{tabular}{|c|c|c|c|c|}
\hline PARAMETER & VALUE & REFERENCE VALUE & PARAMETER & VALUE \\
\hline Haemoglobin (g/dl) & 15.0 & $11.8-15.8$ & Serum IgG/IgA/lgM & Normal \\
\hline Mean corpuscular volume (fl) & 84.4 & $80.4-96.4$ & HIV/ANA/ANCAs & Negative \\
\hline 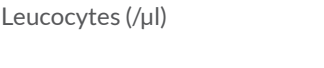 & 12.56 & $4.0-10.0$ & $\begin{array}{l}\text { Anti-transglutaminase/ } \\
\text { antigliadin antibodies }\end{array}$ & Negative \\
\hline Neutrophils $(/ \mu \mathrm{l})$ & 6,280 & $1,800-7,700$ & $\begin{array}{l}\text { Fasciola, Histoplasma, } \\
\text { Entamoeba, Toxocara canis } \\
\text { serologies }\end{array}$ & Negative \\
\hline Eosinophils (/ul) & 3,454 & $<500$ & Urine analysis & Normal \\
\hline Platelets $\left(\times 10^{9} / \mathrm{I}\right)$ & 321 & $150-400$ & & \\
\hline Creatinine (mg/dl) & 0.75 & $0.6-1.0$ & Ascitic fluid analysis & \\
\hline Sodium (mmol/l) & 141 & $136-145$ & Cells $(/ \mu \mathrm{l})$ & 15,646 \\
\hline Potassium (mmol/l) & 3.8 & $3.5-5.1$ & Leucocytes (/pl) & 1,846 \\
\hline C-reactive protein & 2.04 & $0.01-0.82$ & Neutrophils (\%) & 75 \\
\hline Sedimentation rate $(\mathrm{mm} / \mathrm{h})$ & 6 & $4-10$ & Monocytes(\%) & 20 \\
\hline Albumin (g/dl) & 3.3 & $3.5-5.5$ & Lymphocytes (\%) & 5 \\
\hline $\begin{array}{l}\text { Thyroid stimulating hormone } \\
(\mu \mathrm{IU} / \mathrm{I})\end{array}$ & 4.42 & $0.35-4.94$ & Erythrocytes $(/ \mu \mathrm{l})$ & 13,800 \\
\hline $\begin{array}{l}\text { Aspartate aminotransferase } \\
\text { (IU/I) }\end{array}$ & 18 & $8-35$ & Albumin (g/dl) & 3.0 \\
\hline Alanine transaminase (IU/I) & 24 & $7-45$ & Total proteins (g/dl) & 5.0 \\
\hline Alkaline phosphatase (IU/I) & 68 & $30-120$ & $\begin{array}{l}\text { Lactate dehydrogenase } \\
\text { (IU/I) }\end{array}$ & 140 \\
\hline $\begin{array}{l}\text { Gamma glutamyl transferase } \\
\text { (IU/I) }\end{array}$ & 31 & $<38$ & ADA (IU/I) & 10.4 \\
\hline Total bilirubin (mg/dl) & 0.41 & $0.3-1.2$ & Glucose (mg/dl) & 92 \\
\hline Lactate dehydrogenase (IU/I) & 315 & $125-220$ & Amylase (IU/I) & 20 \\
\hline Prothrombin time (sec) & 10.9 & 11.4 & & \\
\hline $\begin{array}{l}\text { Partial thromboplastin time } \\
\text { (sec) }\end{array}$ & 22.1 & 28.0 & & \\
\hline $\lg \mathrm{E}(\mathrm{kU} / \mathrm{I})$ & 62.1 & $<100$ & & \\
\hline
\end{tabular}

Table1. Results of blood tests and ascitic fluid analysis 


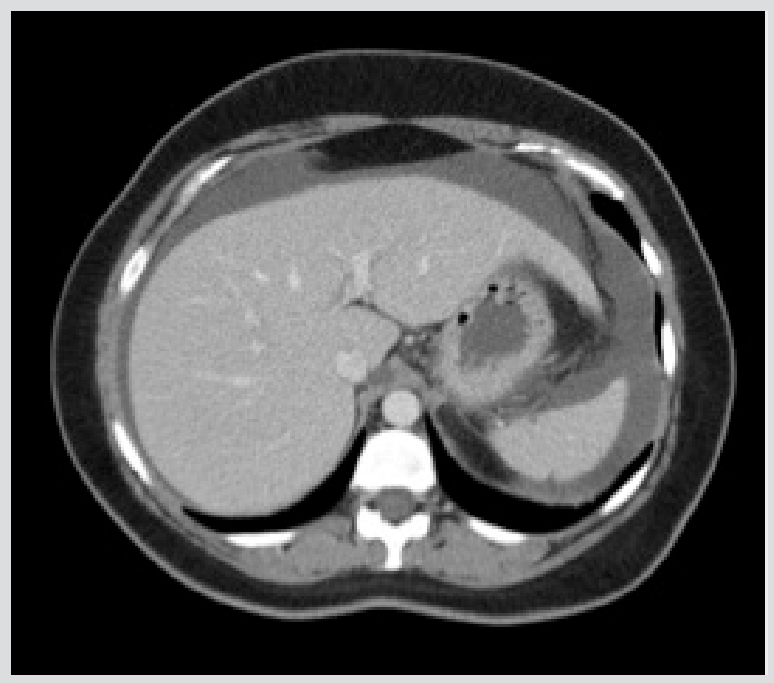

Figure 1. Abdominal computed axial tomography showing ascites and gastric wall thickening

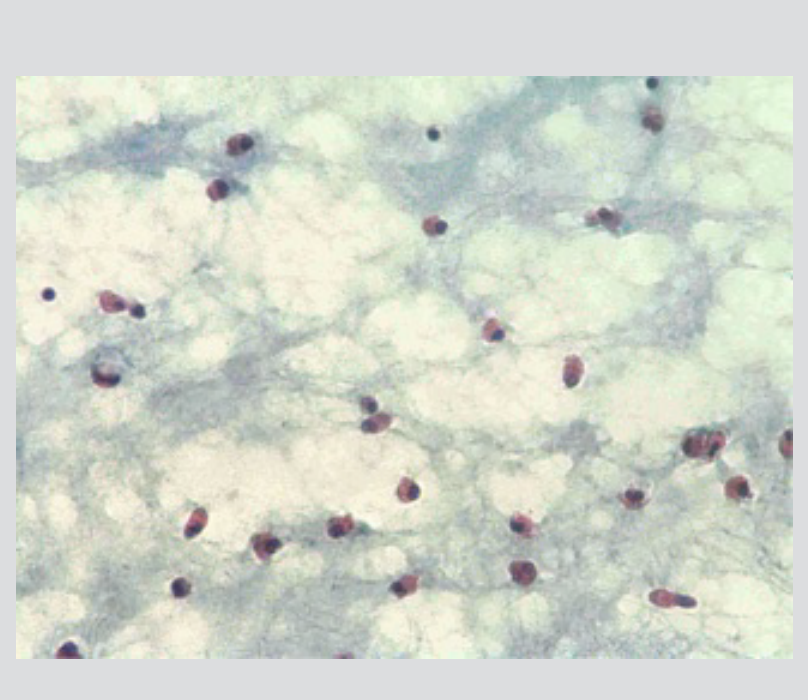

Figure 2. Histological examination of ascitic fluid showing abundant cellularity with inflammatory characteristics with a predominance of eosinophils (40x magnification)

The patient was admitted to our unit and microbiological, mycobacteriological and cytological studies of ascitic fluid were requested. Blood cultures, and microbiological and parasitological stool samples were collected and ceftriaxone $2 \mathrm{~g}$ IV was initiated.

The patient's symptoms and ascites worsened. In light of the clinical findings, ascites with SAG <1.1, peripheral eosinophilia and the imaging results, the differential diagnosis included gastrointestinal tract neoplasia and parasitic infections. Cytological analysis of ascitic fluid revealed inflammatory characteristics with a predominance of eosinophils but with no evidence of malignancy (Fig. 2). Upper and lower digestive endoscopy was normal. A biopsy of the pancreas was performed but there was no evidence of malignancy on histological examination. All microbiological studies including parasitological analysis of the faeces and serology for parasites were negative. Autoantibodies to coeliac disease and an autoimmune study were also negative (Table 1).

Since all studies were negative, eosinophilic gastroenteritis was considered. Upper gastrointestinal endoscopy was repeated and gastric and jejunal biopsy specimens were normal. Due to the absence of eosinophil infiltration in the biopsy specimens, paracentesis was repeated and the predominance of eosinophils in the ascitic fluid was confirmed, a distinct finding compared with the initial automated analysis that showed $75 \%$ of neutrophils, known to be a mistake after discussion with laboratory technicians. The diagnosis of eosinophilic gastroenteritis was made and, given the clinical worsening, corticosteroid therapy with prednisolone $40 \mathrm{mg} / \mathrm{day}$ was started. There was improvement and complete resolution of all symptomatology, ascites and negative analysis findings after 2 months. During follow-up consultation after corticosteroid withdrawal, clinical relapse was observed, so corticosteroid therapy was reinstated. The patient is currently corticosteroiddependent on a daily dose of $5 \mathrm{mg}$ prednisolone.

\section{DISCUSSION}

Eosinophilic gastroenteritis is an uncommon disease but the diagnosis should be considered in the presence of gastrointestinal symptoms or ascites associated with peripheral eosinophilia (>500 eosinophils/ $\mu$ l). The definitive diagnosis is established in the presence of eosinophilic infiltration of the gastrointestinal tract or ascites with a predominance of eosinophils ${ }^{[2]}$. It is mandatory to exclude differential diagnoses ${ }^{[2]}$, namely neoplasms, parasitic infections, inflammatory bowel disease, vasculitis, Langerhans cell histiocytosis and hypereosinophilic syndrome. In our patient, the analytical, microbiological and anatomopathological studies excluded most of the differential diagnoses, leaving hypereosinophilic syndrome which should always be considered in the presence of eosinophilia. This syndrome is characterized

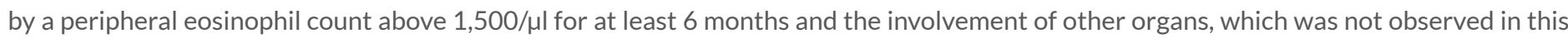
particular case. 
Eosinophilic infiltration is confirmed through multiple gastric and intestinal biopsies as one is not sufficient ${ }^{[3]}$. Diagnosis by biopsy is possible in $80 \%$ of patients ${ }^{[3]}$. However, in isolated muscle or subserous disease, biopsies may be normal ${ }^{[1]}$, which explains the absence of eosinophils in the biopsy performed in the present case, supporting the diagnostic hypothesis of isolated subserous disease.

Spontaneous remission of disease is rare. The scientific evidence regarding treatment is limited, but it is mentioned that the initial approach depends on the severity of the symptomatology. In the initial phase an elemental diet should be tried ${ }^{[2]}$. In the absence of response to dietary changes or in the presence of severe symptomatology, corticosteroid therapy should be considered. Three types of response to therapy are described: (a) complete remission; (b) complete or partial remission in the initial phase but with sporadic flares of disease between months to years apart requiring transient introduction of or increased corticosteroid therapy; and (c) lack of response with a sustained need for lowdose corticosteroids. The recommended dosage in the acute phase is daily $20-40 \mathrm{mg}$ prednisolone and improvement is usually seen within 2 weeks $^{[4]}$. After resolution of symptomatology, corticosteroid therapy should be reduced to the lowest possible dose with the objective of complete suspension.

\section{REFERENCES}

1. Talley NJ, Shorter RG, Phillips SF, Zinsmeister AR. Eosinophilic gastroenteritis: a clinicopathological study of patients with disease of the mucosa, muscle layer, and subserosal tissues. Gut 1990;31:54

2. Ingle SB, Hinge CR. Eosinophilic gastroenteritis: an unusual type of gastroenteritis. World J Gastroenterol 2013;19:5061-5066.

3. Katz AJ, Goldman H, Grand RJ. Gastric mucosal biopsy in eosinophilic (allergic) gastroenteritis. Gastroenterology 1977;73:705.

4. Lee CM, Changchien CS, Chen PC, Lin DY, Sheen IS, Wang CS, et al. Eosinophilic gastroenteritis: 10 years experience. Am J Gastroenterol $1993 ; 88: 70$. 